* Nutricionista-Sanitarista, Secretária de Recursos Humanos do Ministério da Saúde

\section{A Supervisão: Uma Proposta Pedagógica para o Setor Saúde}

\author{
Tania Celeste Matos Nunes*
}

INTRODUÇÃO

A supervisão, eleita pelos ideólogos da gerência científica como um moderno e indispensável instrumento auxiliar da gestão de serviços e sistemas, foi incorporada como conteúdo de administração dos serviços de saúde no Brasil mais precocemente a nivel das unidades hospitalares, mas, toma características de maior realce, nas recomendações relativas à expansão da rede de serviços no Brasil, a partir da década de 70.

A partir de então, esforços vêm sendo desenvolvidos pelos orgãos centrais, responsáveis pela formulação de políticas, no sentido da produção de conhecimentos, incentivos à veiculação de idéias, trabalhos de pesquisa, reunião de técnicos, circulação de documentos específicos, dentre outros, sem que no entanto esse esforço tenha se revertido em interferência na prestação final de serviços, ou mesmo na incorporação de novas formas de administração desses serviços, nos seus vários níveis.

A supervisão continua sendo referida como prática necessária de aperfeiçoamento pelas diversas instituiçōes, sendo que no momento, a estratégia de articulação interinstitucional já acrescenta uma demanda diferenciada, a ser pensada e refletida com a ajuda dessa prática.

Do ponto de vista das instituições, os modelos de supervisão têm variado, pela influência de outras práticas, tais como o planejamento, a administração, a educação, dentre outras, embutidas nos seus próprios processos históricos, enquanto instituições que crescem e se renovam nas suas formas de interagir externa e internamente, seja com a clientela (usuários do serviço) seja entre as instâncias de administração da máquina da prestação de serviços (profissionais do setor).

Assim, nenhum modelo de supervisão pode ser concebido, sem que se considere como ideologicamente as instituiçöes administraram seus processos de trabalho, que por sua vez refletem a forma como a instituição se relaciona com sua clientela na prestação de serviços.

Essas características conferem à supervisão em saúde um contorno especial, de um lado pela dependência que está determinada pela forma de conceber o planejamento desse sistema e de outro pelo modo como ela é convidada a se inserir na produção do trabalho em saúde, tomando como referência as práticas de saúde. A intermediação do componente educati- 
vo parece se constituir numa terceira vertente, recomendada mais recentemente, que, em geral, entre em competição com o seu polo de controle, como um adicional a mais, que na prática não nos parece ter passado de uma "colcha de retalhos" que ainda não conseguiu uma combinação de cores, que a constitua como "conjunto de práticas constituindo uma prática de acompanhamento de sistemas."

Essas constatações históricas e diagnósticas remetem à necessidade de compreender a supervisão e suas determinações, como base das formulaçōes que possam ser feitas, e de seus limites, enquanto prática que, sozinha, não pode dar conta de problemas muitas vezes gerados em esferas de decisão das instituiçōes, mas que merece uma atenção diferenciada, pelas características que hoje assume, a rede de prestação de serviços de saúde no Brasil.

\section{DETERMINANTES DA SUPER VISĀO}

Nesse tópico será transcrito um trecho do documento elaborado pela equipe do Projeto de Supervisão do Ministério da Saúde e Organização Pan-Americana da Saúde - publicado em 1982 e que reúne os elementos básicos para esse tipo de reflexão.

"A supervisão é algo inerente a qualquer processo de trabalho que se realize em bases coletivas, através da divisão e integração de tarefas, entre diversos trabalhadores. Onde as funções de mando (ou gerência) estejam separadas das funções de execução e atribuídas a distintos indivíduos, ela se constitui, inevitavelmente, numa tarefa adicional assumida por quem detém o poder de mando, visando, segundo o objetivos mais ou menos explícitos, a imprimir uma dada orientação ao próprio processo de trabalho.

Quanto mais complexo e hierarquizado for o tipo de trabalho realizado pelo conjunto dos profissionais, mais difusa se tornará a atividade de supervisão, que pode, então, deixar de ser uma prerrogativa dos "chefes" e passar a ser exercida por qualquer pessoa que mantenha uma ascendência técnica ou administrativa sobre outras.

Visto que, em certas instituições, a hierarquização é uma cadeia contínua (cada pessoa é subordinada a alguém e superior a outrem), costuma-se dizer que todo profissional realiza, ou deveria realizar, alguma forma de supervisão, ou seja, acompanhar e orientar o trabalho daqueles perante os quais tem ascendência.

Em certas circunstâncias, sobretudo quando, o trabalho a ser supervisionado ocorre em locais geograficamente dispersos, a supervisão ganha um grau maior de autonomia, aparecendo a figura do supervisor formal, isto $\varepsilon$, uma pessoa designada pela direção para exercício específico (embora nem sempre exclusivo) dessa função e que se desloca regularmente para esses locais de trabalho. Como um intermediário da dire-

Cadernos de Saúde Pública, R.J., 2 (4): 466-476, out/dez, 1986 
ção da instituição em relação ao nível de execução, o supervisor realiza uma função delegada, mas fora da linha de mando, de tal maneira que seu contato pessoal com os supervisionados não se traduz, necessariamente, numa relação de autoridade. Ele é apenas um representante da ascendência técnica ou administrativa da instância de direção.

Numa visão tradicional, atribui-se a esses supervisores o papel de correia de transmissão que, materializando e estendendo a vontade gerencial e sua capacidade de comando, ajusta a execução técnico-administrativa aos padrões e metas previamente definidas por essas instâncias de poder. Para manter a eficiência da instituição, caberia, segundo esse modelo, realizar três atos interligados: conferir (verificar como estão sendo realizadas as ações e sua compatibilidade com as normas), retificar (corrigir a conduta conforme a norma) e informa (dar ciência à direção).

No Brasil, o papel dos supervisores formais em serviços de saúde tem sido objeto de muitos debates, na procura de alternativas adequadas às características sociais e técnicas dos programas de extensão de cobertura de serviços de saúde. Sobretudo, vem-se criticando o modelo gerencial de supervisão acima referido, que pode degenerar tanto uma ação meramente burocrática (restringindo-se aos atos de conferir e informar, de modo pouco criativo e com o preenchimento mecânico de relatórios de rotina) quanto numa atividade de fiscalização estrita (impondo, coercitivamente, o cumprimento de normas). Em qualquer caso, a supervisão deixa de colaborar para que a instituição se afine com os objetivos que lhe são inerentes: servir às necessidades da população. Reconhece-se que, embora também condicionada pelas atitudes e práticas da direção da instituição em seus vários níveis, a supervisão, em programas de extensão de cobertura, não deve reduzir-se a um mero controle da aplicação de normas e padrões de procedimentos, concebidos na cúpula institucional. Entretanto, não pode deixar de efetuar os atos de conferir, retificar e informar, além de instrumentar-se com elementos técnico-administrativos que concorram para melhoria da qualidade e eficiência dos serviços. Assim, a crítica move-se conscientemente entre dois requisitos: o objetivo de tornar a supervisão mais participativa, fazendo com que os supervisores e supervisionados contribuam para a definição e aperfeiçoamento das normas, padrões de atendimento, atividades programadas, etc.; e, por outra parte, a exigência de reter uma eficácia técnica, tendo em vista, em última análise, elevar a própria qualidade da assistência e seu poder resolutivo de problemas de saúde.

Contudo, os contornos dessa nova modalidade de supervisão em saúde, apenas começam a se esboçar e vão-se fazendo mais nítidos, graças à própria prática coletiva dos serviços básicos. Aqui, um dos perigos é cair em propostas, extremamente, abstratas e voluntaristas que, por falta de uma com- 
preensão mais profunda dos determinantes político-institucionais do processo de supervisão, não se apóiem em desejáveis mudanças no conjunto das atividades realizadas pela instituição e em sua maneira de funcionar. Neste caso, a responsabilidade de transformar o processo acaba recaindo, unilateralmente, sobre os ombros dos próprios supervisores, visto que se considera necessário e suficiente modificar a atitude das pessoas.

Por conseguinte, a crítica da supervisão "gerencial" deve remeter, em cada situação concreta, à implantação e continuidade do novo modelo de supervisão.

Em primeiro lugar, cabe aprofundar a análise do condicionamento da supervisão aos dois aspectos fundamentais de uma instituição de saúde: de um lado, a forma como são estruturados e proporcionados os serviços, e, de outro, a maneira como se dão as relações entre as funções de mando e as de execução. Considerados genericamente, esses aspectos têm uma influência marcante quando se passa de uma estrutura de programas especiais a outra, voltada para uma cobertura da população com serviços básicos. Nos programas especiais, a supervisão refletia não só a organização tecnológica destinada ao atendimento de problemas de saúde específicos e de determinadas clientelas, como tamberm o grande distanciamento entre as funções gerenciais e as de execução técnico-administrativa, devido ao relacionamento direto que o nivel central (ou federal) estabelecia com o nível local. Då a existência de supervisores especialistas em atividades de rotina e o caráter verticalizado da supervisão, que seguia, muito de perto, o modelo dito gerencial. Esse tipo de supervisão mostrou-se antagônico aos pressupostos de uma estratégia de cobertura com serviços básicos, que se funda no esforço de equacionamento do conjunto das necessidades de saúde da população e na prestação de uma assistência integral. Assim, ao se transformarem radicalmente a política, a organização dos serviços e as relações de poder, o processo de supervisão precisou ser pensado e reestruturado.

Como um dos elementos determinantes está, em primeiro plano, a própria complexidade técnica da rede, envolvendo uma multiplicidade de categorias profissionais e de unidades prestadoras de serviços, especialmente dispersas, executando ações distintas mais complementares entre si, em consonância com os princípios de regionalização e hierarquização. É consenso que, em grande parte, caberia à supervisão integrar as ações realizadas, conferir um sentido de unidade funcional, para que sejam alcançados os objetivos técnicos, inseparáveis dos fins sociais a que se destinam os serviços básicos de saúde. E isso ela só pode fazer tomando em consideração a totalidade das necessidades de saúde a serem atendidas, segundo uma programação prévia. Impõe-se, em conseqüência, a polivalência como atributo indispensável do supervisor de rotina. 
Ademais, a desconcentração das atividades e a descentralização decisória, imprescindíveis ao bom funcionamento dos níveis hierarquizados de atenção integral, multiplicam os pontos de origem e os fluxos de supervisão criando instâncias administrativas intermediárias, que podem auxiliar na diminuição da distância e das contradiçōes entre funçōes de mando e de execução. É compreensível que a centralizaçāo administrativa favoreça o aparecimento de atitudes autoritárias por parte dos supervisores, que tendem a se comportar como fiscais encarregados de flagrar os supervisionados em seus erros e omissöes. Ao contrário, a descentralizaçāo, evidentemente, contribui para que os conteúdos e o procedimento de supervisão sejam estabelecidos e modificados de acordo com necessidades detectadas no nível de execução. Deste modo, a descentralizaçāo decisória, ao aproximar o mando da execuçāo, é condiçāo indispensável para o florescimento de uma variedade mais participativa de supervisão.

Essa supervisão participativa não elimina a autoridacle dos niveis de direção, mas apenas os torna mais hexíveis, no escopo de responder prontamente às exigências da prática dos serviços e, por läm, das próprias necessidades de saúde da população. Isto deve resultar de um esforço global da instituição, no sentido de melhor distribuir o poder de decisão e de intervençāo. Sabe-se, entretanto, que o esforço descentralizador só alcançará os objetivos a que se propōe quando esse poder for conquistado e mantido pelos níveis local e regional, e não ser simples dádiva da administração central, yue a qualyuer momento pode subtraí-la.

lodas essat questōes referentes à estrutura dos serviços o relaçoes de poder deveräo ser analisadas, numa dada conjuntura, para yue se determinem as catracterísticas a serem assumidas pela supervisão, supondo-se yue cla possa ser planejada em todas suas linhats. I udo isso nos condur à conclusão de yue as mudanças preconiatdas näo dependem apenas de tatores subjetivos ligados a preparaciano e quadidades pessoais dos supervisores. Dependem, isto sim, de decisées políticas no âmhito das instituceres e de correspondentes medidas administrativas que levem à formulacäa e desenvolvimento de modelos alternatuvos de supervision.!

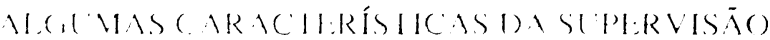 1:115.11)1:}

(1) Crescumento do volume de estudos (lesse tema especílico, remete à necessidade de compreendê-lo nos seus determinante maiores, como forma de encaminhar questões com base em elementos da realidade, mas entendendo os limites que essa prática apresenta, enquanto prática técnica.

A expansão dos serviços e o surgimento de uma rede com características descentralizadas, vieram a requerer uma nova 
forma de pensar a administração e o acompanhamento da qualidade dos serviços, ao mesmo tempo em que se propõe a acompanhar $\mathrm{o}$ aumento ordenado ou desordenado dessa rede.

Aqui se encontram dois dos grandes problemas encontrados pela supervisão:

- a que se propõe a supervisão, um acompanhamento da produção do serviço técnico médico em saúde, ou o acompanhamento técnico da produção do serviço em saúde?

- qual o tipo de profissional que dará conta de um ou de outro modelo, o que se chamou tradicionalmente de generalista ou o polivalente?

Essas interrogaçōes geram una terceira questão que propōe a combinação de ambas quando diz:

- há necessidade e espaço para que a supervisão dê conta de um acompanhamento da açāo de saúde, e nesse caso haverá lugar para o supervisor polivalente e o supervisor especffico?

No entanto antes de discutir essas questōes parece interessante considerar como nesses modelos se constitui o processo de supervisāo e de escolha do supervisor, num plano mais abstrato, que é o que determina a existência da própria supervisão.

A revisão da titeratura sobre o tema nos refere que essa prática tem suas origens na instituiçāo da gerência cientifica, "que divide o trabalho entre lugares distintos e distintos grupos de trabalhadores. Num local, são executados os processos tísicos da produção, num outro estão concentrados o projeto, planejamento, cálculo e arquivo. ${ }^{3}$

Esse princípio nos parece de fundamental importância considerar, yuando o setor saúde incorpora a supervisão como prática ligada ao controle da programação e escolhe para isso alguns técnicos com um certo preparo intelectual sobre a forma como o serviço se organiza, e outros com alquma experiência na prestação de serviços, mas que é retirado do processo de trabalho, passando a fazer parte de um grupo que irá executar atividades mais reflexivas ou controlistas, passando a considerar mais os aspectos de gerência do serviço, do que a sua efetividade vinculada aos fins específicos a que se propōe.

Esse tipo de pensar parece reforçar o componente de controle, tão exacerbado nas estratégias de supervisão, em que o gerente/supervisor que é retirado da prestação de serviços, passa a ter agora "obrigações com a gestão do Programa" devendo "cobrar" da equipe que presta serviços uma eficiência estabelecida pelas instâncias de planejamento, que concebem mas não atuam nessa prestação de serviços.

De outro modo, o objeto da supervisão parece disperso entre profissionais e serviços pelas características do trabalho de saúde, que não se encerra num setor ou departamento, mas completa entre os diversos setores, departamento e vários re- 
cortes de profissionais, constituindo o que se constuma chamar de trabalho coletivo, executado por equipe multidisciplinar.

Assim, considera-se impossível pensar a quéstão da supervisão pessoa a pessoa, ou pessja/supervisor a setores ou profissionais específicos, como em outros setores da produção, de onde se importou a maioria das técnicas utilizadas na supervisão.

Outro capítulo da administração que parece importante considerar aqui $\varepsilon$ o que se segue ao movimento da gerência científica e que visa "alcançar formas de ajustar o trabalhador ao trabalho, em sua forma capitalista, de superar a resistência natural intensificada pela tecnologia mutável e alternante, relações sociais antagônicas". "Em conseqüência disso, surgiram dentro dos departamentos de pessoal e de relações trabalhistas, nas organizações de apoio externas, escolas como a de relações industriais, departamentos universitários de sociologia e outras instituições acadêmicas, destinadas ao estudo do trabalhador. ${ }^{3}$

Nessa abordagem, "os problemas em foco são os de gerência: insatisfação expressa pelas elevadas taxas de abandono de emprego, absenteísmo, relutância ao nível de trabalho imposto, indiferença, negligência, restriçōes à produção, e hostilidade ostensiva à adninistração. ${ }^{5}$ Essa interpretação reduz a problemas de prestação de serviços à área comportamental, tangenciando os aspectos de produção do trabalho, e no caso da saúde, da compreensão dos processos saúde/doença, determinantes institucionais da prestação e da gerência de serviços, assim como os aspectos contidos na compreensão da clientela dos serviços de saúde como forma social viva, determinante das formulações e reformulaçōes da prestação de serviços e componente maior de compromisso do setor.

Essas consideraçōes, longe de se tornarem intermináveis nesse texto, têm apenas o propósito de trazer para a reflexão, elementos que não podem ser desprezados na formulação de qualquer proposta, sob pena de se incorporar dados ingênuos em proposições tão complexas, e que tem origens históricas na constituição do próprio trabalho.

\section{CONSIDERAÇŌES PARA FORMULAÇÕES DE MODELOS}

Diante dos aspectos considerados $\varepsilon$ evidente que não existe modelo univeral de supervisão, nem mesmo um modelo único aplicável às instituições de saúde no Brasil.

É também considerável o estágio de transição que vive hoje o sistema de saúde diante da perspectiva de construção de um sistema unificado que tem suas bases em debate e elaboração, o que seria o conteúdo fundamental para fornecer elementos que venham subsidiar um modelo apropriado de supervisão. 
No entanto, linhas gerais podem ser estabelecidas, coerentes, cuin as propostas de sistemas de saúde preconizadas pela 8a Conferência Nacional de Saúde, acrescida dessas e outras reflexões sobre o tema, bem como, fruto da critica e da contribuição do trabalho de profissionais que vêm há algum tempo exercendo ou estudando essa função.

1. Poder-se-ia considerar como fundamental e ponto de partida, a compreensão de que o processo de supervisão começa a ser desenhado, junto com o processo de planejamento e programação.

Numa concepção de que não é possível obter-se participação, alienando-se os trabalhadores que prestam serviços, pressupōe-se que a programação alcance níveis cada vez mais periféricos do sistema de saúde. Assim, o desenho do acompanhamento nascerá sobre duas vertentes:

- o da organicidade com o planejamento e a programação.

- o da participaçāo entre planejadores/supervisores e prestadores de serviço (profissionais de saúde).

2. Outra consideração a ser feita é de que a prestaçāo de serviços de saúde de forma coletiva não comporta mecanismos de supervisão que individualizam as açōes. Assim, a consulta médica, se completa com a atuação da enfermagem e de outros serviços, começando pela triagem de unidade passando pelo apoio diagnóstico, pelo serviço de arquivo médico, e sendo intermediado por todo o esquema administrativo e de apoio das unidades. Nesse caso, os processos de supervisão devem dar conta de uma avaliação de atos médicos, ou outras formas de prevenção ou controle de agravos à saúde que não se encerrem na relação supervidor $x$ supervisionado, mas sim, numa avaliação da prestação de serviços, incluindo e agregando os elementos que forem necessários a essa avaliação.

3. Sendo um forte instrumento de detecção de problemas (embora não possa se encerrar nesse objetivo sob pena de empobrecer a sua perspectiva) a supervisão deve ter a característica de retornar, imediatamente, a informação coletada pela instância que supervisiona, para a instância que presta serviços.

A desmonopolização do saber pelo supervisor, nesse caso, deverá proporcionar elementos de reflexão pela equipe supervisionada, que deverá tomar conhecimento de como o seu trabalho fracionado está contribuindo ou não na construção do coletivo daquela unidade prestadora de serviços.

4. A continuidade do processo e fator fundamental para manter o conteúdo de acompanhamento de uma programação partilhada e participativa, que tem sérios aspectos de emperramento nos niveis mais centrais, e a supervisão deve ser um canal que desobstrua os entraves dessa relação entre os níveis. No entanto, é necessário que ela tenha poder de resolutividade, junto ao coletivo, onde ela está se dando, devendo, por isso, o supervisor buscar o respaldo necessário ao exercício legítimo da sua função. 
5. A educação continuada é um dos subprodutos desse trabalho e como tal deve buscar formas criativas de desenhar esse processo entre supervisores e supervisionados. Tendo claro que o seu conteúdo são os próprios tementos do acompanhamento, sem o qual bem definido, poderá se cair na linha comportamental vazia de conteúdo referida anteriormente. Um trabalho de educação continuada via supervisão poderá ser gerado nos núcleos de supervisão em qualquer nível do sistema com o participaçāo de supervisores e supervisionados, que farão do debate das dificuldades e avanços do processo da prestação de serviços uma fonte contínua e sistemática de aprendizado.

Uma concepşão pedagogica da supervisão no setor público - elementos para reflexão de uma nova ética.

O exercício de reflexão sobre esse tema, diante das proposiçōes da Conferência Especifica de Recursos Humanos, parece-nos insinuar a necessidade de relacionar aspectos ainda não contemplados pelo texto da prestação de assistência à saúde, e de grande relevância, para uma nova compreensāo da supervisâo, como instrumento estratégico de revitalização dos processos administrativos do setor e também dela resultante.

A revisão de literatura e as abordagens, aqui realizadas, parecem indicar que não se aplicam aos mecanismos de constituição dessa prática no setor público de saưde, os aspectos entre produção do trabalho e lucro, do ponto de vista concreto, o que poderia ser motor de uma outra compreensão de gerência, de uma outra prática de supervisão, nos moldes que ela se conforma e como a utiliza o setor produtivo, ou mesmo o setor privado de saúde.

Nesse caso, o exercício do trabalho do supervisor teria características bastante próprias, com uma forma aderente is ordens de uma chefia maior e sua identificação com essa linha de autoridade do patrão, levaria a formas diferenciadas de exercício dessa autoridade junto aos supervisionados.

No setor público de saúde dois elementos parecem estabelecer a diferença dessa abordagem: 1. o patrão não está representado pela chefia e sim pela população, cujos orgãos de governo devem representar formalmente no seu exercício de autoridade, uma delegação dessa pupulação. 2. a logica do lucro não está presente entre "chefécs não-patrōes" c subordinados, uma vez que o lucro estaria aqui representado pelo beneffcio social atribuído por esse tipo de serviço, e comumente não avaliado pelas instituições.

Mesmo nessa perspectiva resta à supervisão as funçōes de controle e de desenvolvimento da força de trabalho que está dispersa na rede, seja de gerência intermediária, seja na prestação de serviços propriamente dita.

Assim entendidos, esses dois componentes não se reúnem para constituir uma função que dê conta das duas fïnalidades ao mesmo tempo, mas parece claro que o controle estaria a 
serviço de um tipo de objetivo, enquanto que a educação faria o pólo da preocupação pedagógica na prestação de serviços.

() ponto de encontro dessas duas finalidades seria a defini(āo dos contélílos, uma ve $z$ que ambos não existem como fins em si mesmos, mas, para instrumentalizar outras práticas de conteúdos próprios, que são as práticas de saúde.

Parece, assim, fundamental contemplar aqui a necessária inter-relação que teria um mecanismo como esse, das práticas de planejamento; essas referindo elementos, para a constituição do trabalho da supervisão, ao mesmo tempo alimentando o que se cspera do controle ou da educação no desenvolvimento das ações de supervisão.

Nesse sentido, reitera-se que as estratégias de planejamento devem contemplar a participação dos supervisores, o que scria uma forma de habilitação para um exercício mais comprometido com o trabalho a ser acompanhado.

Assim, o deslocamento do polo de discussão sobre a convivência entre o contole e a educação, ambos elementos constitutivos da supervisão, poderia se dar no sentido de aperfeiçoar as técnicas de incorporação e viabilização desses dois objetivos, com estratégias que venham recuperar a questão do trabalho coletivo em saúde e sua finalidade, quando inserido no setor público.

As práticas pedagogicas poderão dar conta de uma conduf̧ão que contemple essa perspectiva, numa linha de crescimento coletivo dos trabalhadores, onde as definiçōes possam ser tomadas com base em informaçöes democratizadas e mecanismos de gestão que possibilitem o crescimento técnico das equipes, em torno de objetivos sociais dos serviços de saúde, e que esses objetivos sociais possam ser o móvel de uma nova forma de se organizar a prestação de serviços, estruturando a cada passo da participação social uma forma mais democrática de realizar a supervisão, a caminho de um controle social que deslogue para a base, os aspectos relativos à supervisão, sem no entanto desprezar a necessidade de controle dos níveis mais centrais e colocando o IRABAIIH() (OMPRO ()METIDO como o ponto de encontro dos interesses entre as instituições, que devem representar o que espera e avalia a população, no dia-a-dia, de usuária desse TRABALHO.

BIBISIOCRAIA CONSHI,IAI)A

1. BRASII. Mınısterio da Saúde. Supervisão em serviços hásicos de sanide. Braślat Centro de l oxumentação do Ministério da Saúde, $19 \times 2.19$ p. (l'extos hásicos de saúde, 1).

2. BRAVERMAN, H. A Habituação do trabalhador ao modo capitalista de produção. In: Trabalho e capital monopolista: a degredação do trabalho no seculo XX. 3. ed. Rio de Janeiro, Zahar, 1981. p. 124-34.

3. BRAVIRRMAN, H. Principais efeitos da gerência cientifica. In: Trabalho e capital monopolista: a degradação do trabalho no século XX. e. ed. Rio de Janeiro, Lahar, 1981. p. 112-23. 
4. NUNES, T.C.M. A supervisão em saúde: um estudo exploratório em instituiçōes públicas no âmbito federal e estadual. Salvador, 1986. 230p. [Dissertação de Mestrado, Faculdades de Medicina UFBa].

5. SILVA, Correia da \& SIRIA, M. Supervisäo educacional: uma reflexão crítica. Petrópoli s, Vozes, 1981. 103 p. 